\title{
A MORPHOLOGICAL STUDY OF BACTERIAL COLONISATION OF INTRAVENOUS CANNULAE
}

\author{
J. S. Cheesbrough, T. S. J. Elliott* and R. G. Finch
}

Department of Microbial Diseases, The City Hospital, Nottingham NG5 1PB and

${ }^{*}$ Department of Microbiology and PHLS Laboratory, University Hospital, Nottingham $N G 72 U H$

\begin{abstract}
SUMMARY. In an investigation of bacterial colonisation of intravascular cannulae, 16 peripheral venous cannulae of the Venflon variety and 24 chronic haemodialysis cannulae were studied after removal from patients. Studies of colonisation included semi-quantitative microbiological culture and scanning electronmicrographic (SEM) observations. The microbiological findings indicated colonisation of the intravascular portion of the catheter in 4 of 16 Venflon cannulae and 18 of 26 haemodialysis cannulae, largely with skin commensal organisms. The results of the SEM studies were in broad agreement with the microbiological observations. Surface defects on the cannulae were shown to be associated with microbial colonisation which occurred either as isolated colonies or in association with a cellular fibrinous matrix. These observations are illustrated and discussed.
\end{abstract}

\section{INTRODUCTION}

Infection is a common complication of intravenous cannulation, yet the mechanisms whereby microorganisms colonise these cannulae remain uncertain. Recent in-vitro studies have suggested that surface defects in the cannulae favour bacterial attachment and subsequent colonisation (Locci, Peters and Pulverer, 1981b). The production of slime and the breakdown of catheter components by bacteria may promote such colonisation (Peters, Locci and Pulverer, 1982). Moreover, it has been shown that intravenous cannulae provoke a tissue response that results in the formation of a fibrin sleeve around the cannula (Hoshal, Ause and Hoskins, 1971). Attachment of microorganisms to the fibrin rather than the cannula surface may also be important in establishing colonisation.

To further elucidate the bacterial colonisation of intravenous cannulae, the morphological appearances of two types of cannulae removed from patients after various periods of time were studied by scanning electronmicroscopy (SEM). The cannulae were simultaneously studied for microbiological evidence of colonisation, and the clinical condition of each patient was recorded. 


\section{MATERIALS AND METHODS}

Cannulae. Two types of cannula were investigated: the Venflon ${ }^{\circledR}$, a Teflon cannula with an integral valved side-port manufactured by British Viggo, Swindon, Wiltshire, and a Teflon haemodialysis cannula manufactured by Kimal, Uxbridge, Middlesex. These were obtained from 16 patients in the coronary care unit with short-term peripherally sited Venflon cannulae, and 24 patients with long-term subclavian haemodialysis cannulae. The Venflon cannulae were in situ for a mean of $50.3 \mathrm{~h}$ (range 10-119 h) and the haemodialysis cannulae for a mean of 27.3 days (range 1-94 days). In each case, the inner and outer surfaces of the cannulae were examined microbiologically and by SEM.

Microbiological studies. After careful aseptic removal of the cannula, the distal $1 \mathrm{~cm}$ was cut off and prepared for SEM. The remainder of each Venflon cannula and the remaining distal $5 \mathrm{~cm}$ of each haemodialysis cannula was processed by a roll culture technique (Maki, Weise and Sarafin, 1977). This method yields a semi-quantitative estimate of cannula colonisation in which a growth of $\geqslant 15 \mathrm{cfu}$ is regarded as significant. The lumen was then flushed with $1 \mathrm{ml}$ of nutrient broth which was spread over the surface of a blood-agar plate. Any growth exceeding $15 \mathrm{cfu}$ was regarded as significant in this culture. The distal $1 \mathrm{~cm}$ of a cannula of each type was cut off immediately after removal from its sterile package, to provide controls.

Scanning electronmicroscopy. The tip was fixed immediately in glutaraldehyde $5 \%$ in $0.05 \mathrm{M}$ sodium cacodylate containing $10 \mathrm{mM} \mathrm{MgSO}_{4}$ for at least $1 \mathrm{~h}$ at $20^{\circ} \mathrm{C}$, and then cut longitudinally in half. The halves were washed twice for $10 \mathrm{~min}$ in the same buffer and then dehydrated sequentially with $25,50,70,90,95$ and $100 \%$ buffered alcohol. They were then placed in $100 \%$ acetone and dried in a critical point drier (Polaron Equipment Ltd, Watford, Herts). They were mounted on scanning stubs and coated with gold for $2 \mathrm{~min}$ in a splutter coater (E. M. Scope, Ashford, Kent). Electronmicrographs were obtained with the scanning facility of a Joel $100 \mathrm{C}$ microscope.

\section{RESULTS}

\section{Microbiological findings}

Haemodialysis cannulae were obtained from 24 patients. Six yielded no growth, two gave mixed growths of Staphylococcus epidermidis with a Bacillus sp. or S. aureus, and 16 cannulae were shown to be colonised with one species: $S$. epidermidis $(8), S$. aureus (5), Pseudomonas sp. (2) and Candida albicans (1). Thirteen of the colonised cannulae were associated with clinical sepsis.

Venflon cannulae were removed from 16 patients. Four of these were colonised with $S$. epidermidis, but none was associated with septicaemia. The remaining Venflon cannulae were sterile. The results of roll and luminal culture were similar in all the haemodialysis cannulae and three of the four colonised Venflon cannulae, but one of the latter appeared to be colonised purely on the external surface.

\section{Morphological appearance of tips}

The control haemodialysis cannulae had numerous small pits on their inner and outer surfaces which were ridged along the longitudinal axis (fig. 1A). At the distal tapered end the ridges were more prominent and the cut edge irregular (fig. 1B). The control Venflon tip also had longitudinal ridges on both surfaces (fig. 2), but these were less pronounced than those on haemodialysis cannulae. Surface pits on the Venflon cannulae were less numerous and smaller than those observed on the haemodialysis cannulae. 

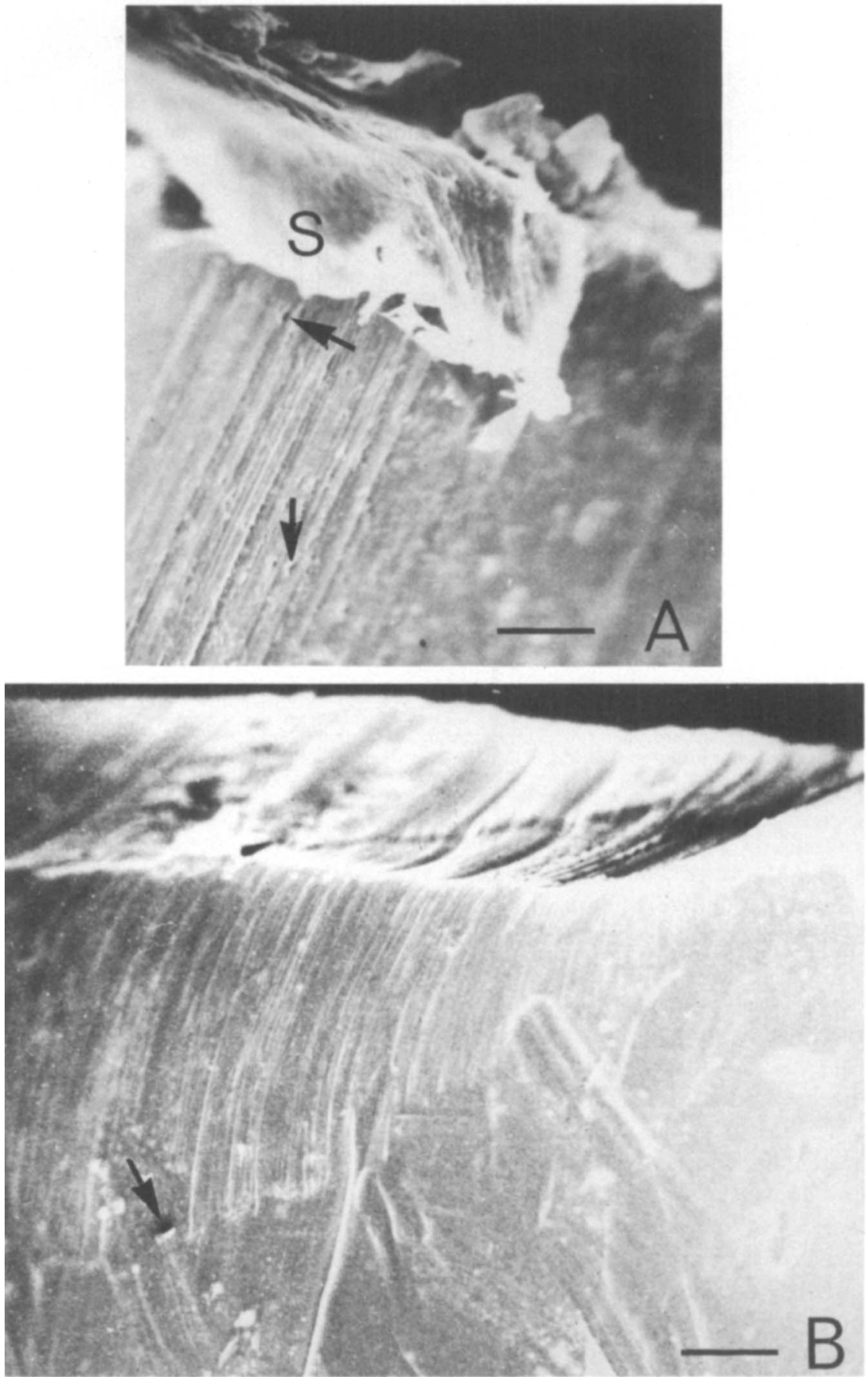

Fig. 1.-Scanning electronmicrographs of tips of unused (control) haemodialysis cannulae: (A) inner distal surface, and (B) outer distal surface. Both show ridged surfaces and pits (arrowed). 1(A) also shows a distorted edge (S). Bar $=1 \cdot 0 \mu \mathrm{m}$. 


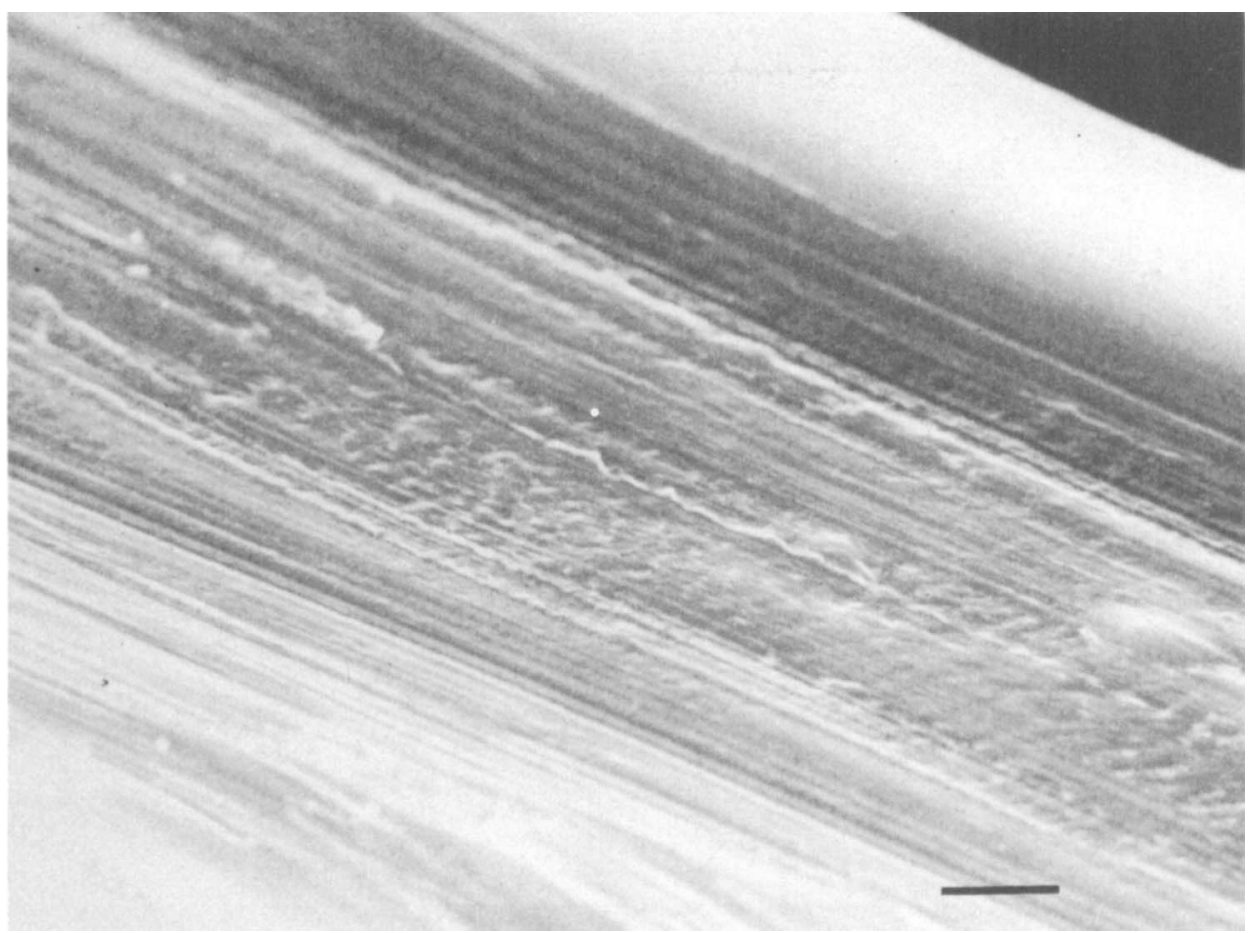

FIG. 2.-Scanning electronmicrograph of inner surface of the distal end of a Venflon intravenous cannula showing irregular longitudinal ridges. $\operatorname{Bar}=1.0 \mu \mathrm{m}$.

The tips of virtually all the cannulae removed from patients had deposits of fibrinous material on their inner surfaces. This material of ten covered the entire surface of cannulae which had been in situ for more than $72 \mathrm{~h}$. On the inner surfaces of the Venflon cannulae, individual adherent cells resembling macrophages with extensive processes were often seen (fig. 3A). The processes of these cells were intertwined with fibrin and formed an extensive matrix on the cannula surface. Within this matrix occasional erythrocytes and neutrophils could also be seen. The outer surfaces generally had fewer cells and less fibrinous material.

The haemodialysis cannulae, which were in situ for longer periods, had more extensive areas of cellular fibrin matrix than had the Venflon cannulae. This material was present on their internal and external surfaces and in some areas had accumulated to form a dense network (fig. 3B).

Bacteria were observed on both types of tips. Of the 18 haemodialysis cannulae from which organisms were isolated, 10 definitely had bacteria observed by SEM, six were possibly colonised, and two were completely free from bacteria. Three of the six culture-negative haemodialysis cannulae showed no organisms by SEM. In the remaining cannulae the extensive accumulation of fibrinous material made it difficult to be certan that bacteria were absent. Four of the 16 Venflon cannulae yielded bacteria on culture, and 12 yielded no growth. Bacteria were visualised by SEM on three of the four that were culture-positive and on five of the 12 that were culture-negative.

The bacteria observed on the Venflon cannulae were present in several different 

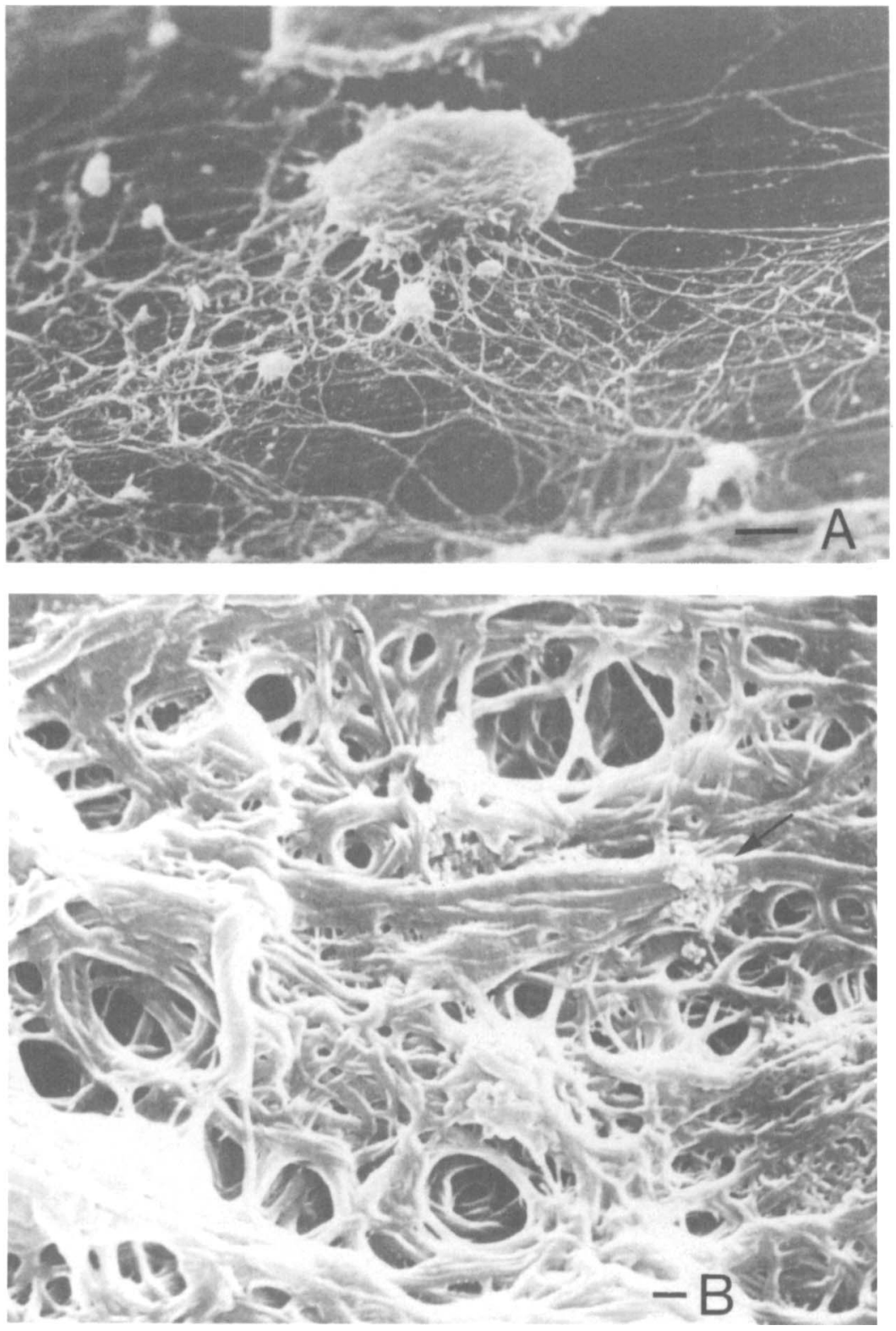

FIG. 3.-Scanning electronmicrographs showing (A) the inner surface of a 'Venflon' tip with an adherent cell with numerous fibrinous processes, and (B) the inner surface of the tip of a haemodialysis cannula bearing a mass of interwoven fibrinous matrix with clusters of bacteria $\mathrm{Bar}=1.0 \mu \mathrm{m}$.

arrangements. Most commonly, single or small clusters of organisms were present (fig. 4A). Discrete discoid microcolonies with well defined margins, apparently associated with surface defects, were also seen on some of the haemodialysis cannulae (fig. 4B). The organisms within these colonies appeared to be distributed around strands of fibrinous material; the surface of the cannula within the confines of these colonies was 

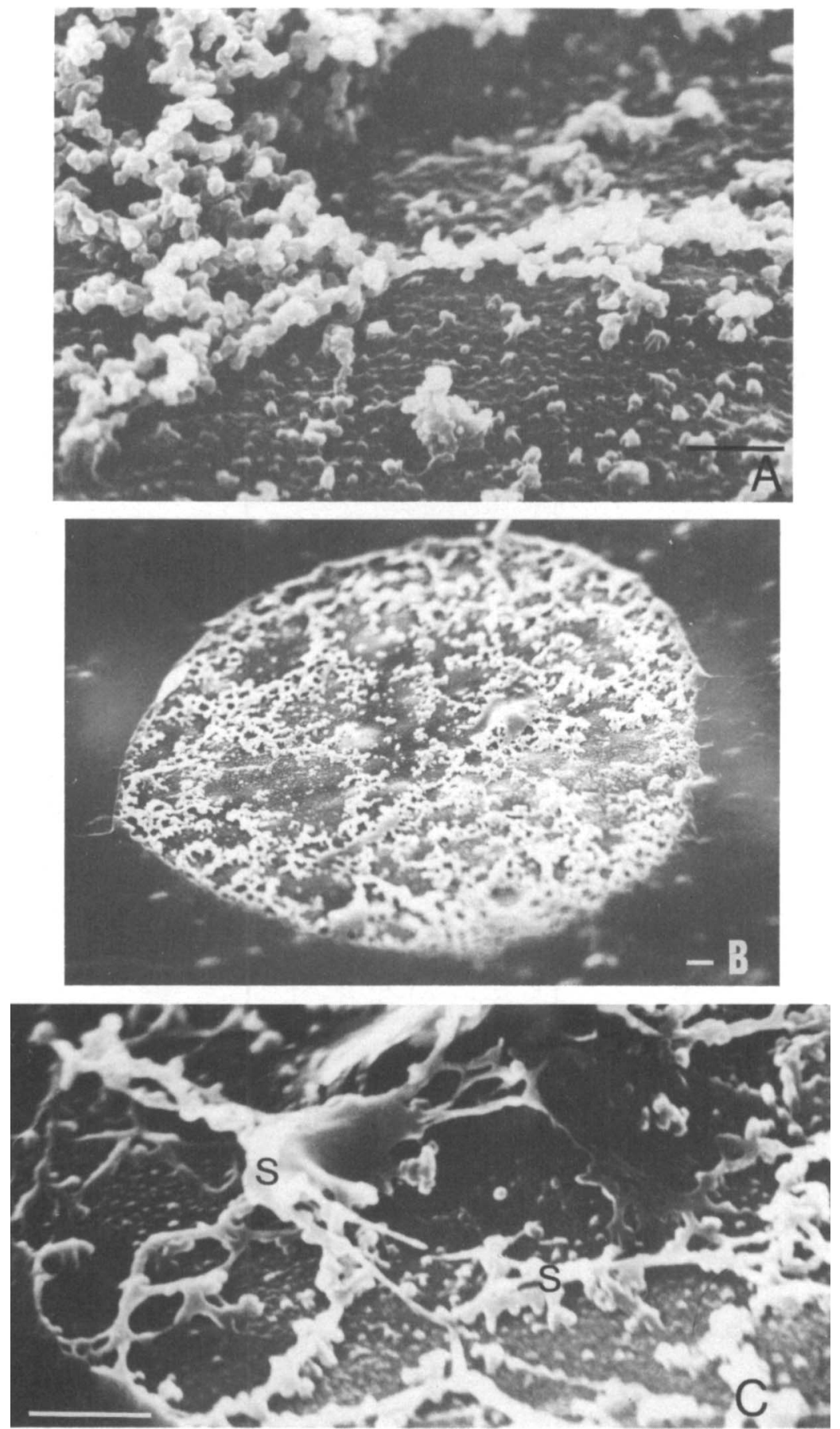

Fig. 4.-Scanning electronmicrographs of cannula tips showing (A) numerous bacteria on an irregular inner surface of a 'Venflon' cannula, and (B) a discoid microcolony on the inner surface of a haemodialysis cannula. At higher magnification (C) the cannula surface under these discoid colonies appears uneven whereas the surrounding surface is smooth. Interspersed with the colony is some material that forms strands (S). Bar $=1 \cdot 0 \mu \mathrm{m}$. 

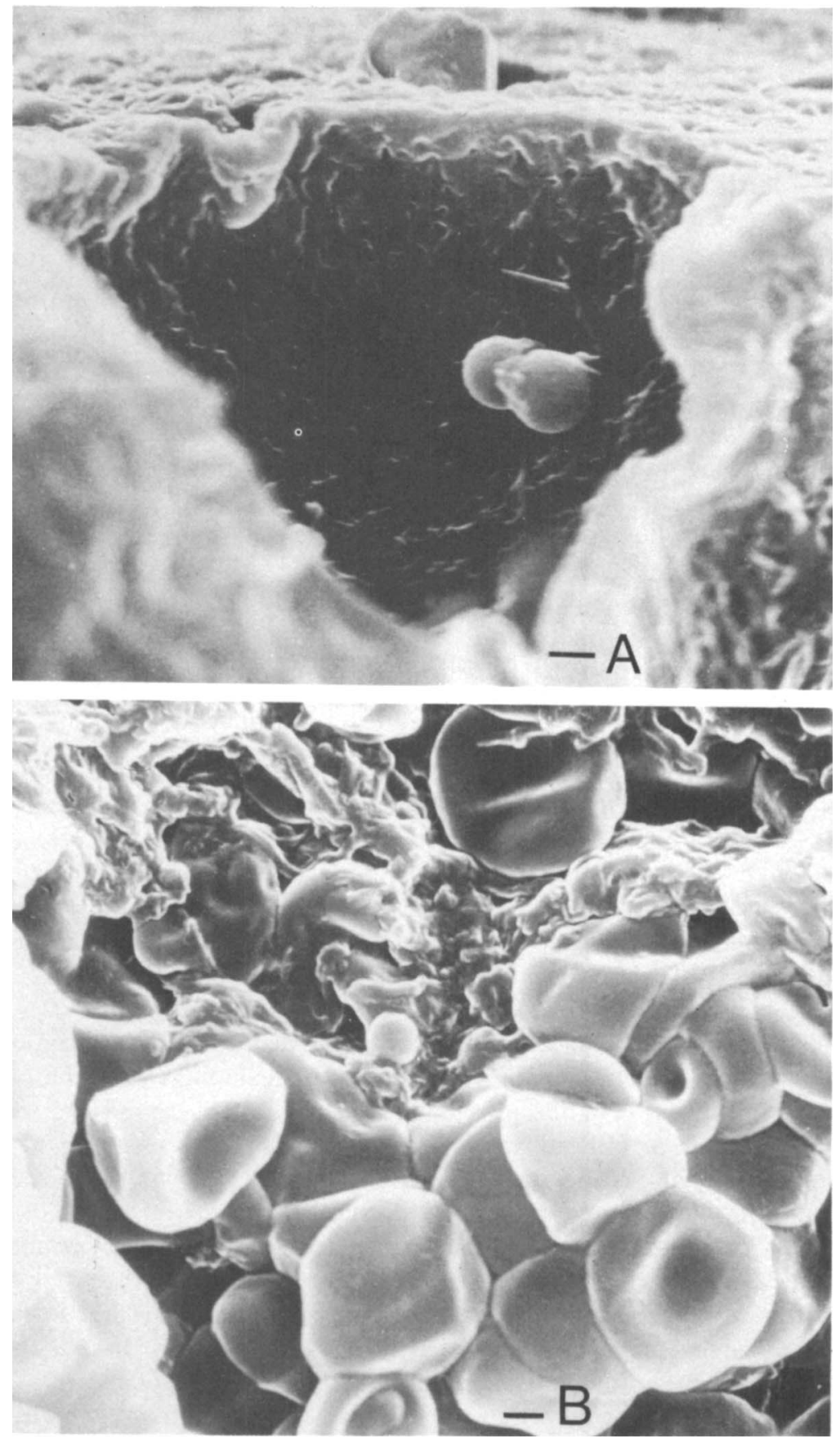

FIG. 5.-Scanning electronmicrographs of the inner surface of a haemodialysis cannula tip showing (A) a surface pit containing two bacteria, and (B) a bacterium amongst a matrix of erythrocytes and fibrinous material. $\operatorname{Bar}=1 \cdot 0 \mu \mathrm{m}$. 
covered with numerous small particles (fig. 4C). On the dialysis cannulae, organisms were often seen residing in surface pits (fig. 5A). Occasionally, aggregates of bacteria were seen on irregular areas within fibrinous material and between erythrocytes in clots (fig. 5B).

\section{Discussion}

This study has demonstrated that intravenous cannulae in situ rapidly become coated with a cellular fibrinous matrix, which appears to accumulate with time. Clusters of bacteria could be seen within this matrix, as previously reported by Hoshal et al. (1971).

It has been previously demonstrated that irregularities of cannula surfaces are common (Locci, Peters and Pulverer, 1981 $a$ ) and are favoured sites for microbial adherence and colonisation in in-vitro studies (Locci et al., 1981 b). In the present study an association between surface irregularities, especially pitting, and bacterial attachment was observed. The relationship between the discoid microcolonies and surface irregularities remains unclear; the well defined edge of a discoid colony and the distribution of organisms within the lattice suggests that fibrin deposition on a surface defect may be the initial step in its formation. On the other hand, surface defects may be secondary to microbial colonisation. This theory is supported by reports that some strains of $S$. epidermidis may cause erosion of the surface of a variety of cannula types, including those made of Teflon (Peters et al., 1982).

Previous in-vivo and in-vitro SEM studies of infected cannulae have strongly indicated that bacteria accumulate within amorphous extracellular glycocalyx material (Peters, Locci and Pulver, 1981; Christensen et al., 1982). Indeed the glycocalyx can obscure individual bacteria so that they may not be detected by SEM. The capacity of strains of $S$. epidermidis to produce such material appears not only to promote adherence to cannulae but also to be a virulence factor for cannula-related sepsis in an animal model (Christensen et al., 1983) and in clinical practice (Bayston and Penny, 1972).

In our study there was no clear evidence of extensive intra-luminal accumulation of glycocalyx in any of the cannulae. This contrasts with the findings of Peters et al. (1981) who noted little deposition of fibrinous material. These differences may reflect the type of cannula studied. Significant factors may be that dialysis cannulae are used intermittently and that the fenestration in a dialysis cannula allows blood to bathe both internal and external surfaces of the tip continuously.

There was broad agreement between our microscopic observations and culture findings. The discrepancies could be due to a number of factors, including sampling errors attributable to the inevitably limited areas of cannula surface scanned, our difficulty in distinguishing organisms within fibrinous deposits, and the possible failure of some visualised organisms to grow in subsequent cultures in vitro.

This study supports the view that the capacity of bacteria to adhere directly to a cannula surface and their capture within a deposited fibrin sleeve are important steps in colonisation. In the case of long-term haemodialysis cannulae our observations suggest that the fibrinous sleeve appears to play a dominant role in promoting colonisation. 


\section{REFERENCES}

Bayston R, Penny S R 1972 Excessive production of mucoid substance in Staphylococcus S II A: a possible factor in colonisation of Holter shunts. Development Medicine and Child Neurology (Suppl) 27:25-28.

Christensen G D, Simpson W A, Bisno A L, Beachey E H 1982 Adherence of slime-producing strains of Staphylococcus epidermidis to smooth surfaces. Infection and Immunity 37:318-326.

Christensen G D, Simpson W A, Bisno A L, Beachey E H 1983 Experimental foreign body infections in mice challenged with slime-producing Staphylococcus epidermidis. Infection and Immunity 40:407-410.

Hoshal V L, Ause R G, Hoskins P A 1971 Fibrin sleeve formation on indwelling subclavian central venous catheters. Archives of Surgery 102:353-358.

Locci R, Peters G, Pulverer G 1981 a Microbial colonization of prosthetic devices. I. Microtopographical characteristics of intravenous catheters as detected by scanning electron microscopy. Zentralblatt für Bakteriologie Mikrobiologie und Hygiene I Abt. Orig. B 173:285-292.

Locci R, Peters G, Pulverer G $1981 b$ Microbial colonization of prosthetic devices. III Adhesion of staphylococci to lumina of intravenous catheters perfused with bacterial suspensions. Zentralblatt für Bakteriologie Mikrobiologie und Hygiene I Abt. Orig. B 173:300-302.

Maki D G, Weise C E, Sarafin H W 1977 A semi-quantitative culture method for identifying intravenous-catheter-related infection. New England Journal of Medicine 296:1305-1309.

Peters G, Locci R, Pulverer G 1981 Microbial colonization of prosthetic devices. II. Scanning electron microscopy of naturally infected intravenous catheters. Zentralblatt für Bakteriologie Mikrobiologie und Hygiene. I Abt. Orig. B 173:293-299.

Peters G, Locci R, Pulverer G 1982 Adherence and growth of coagulase-negative staphylococci on surfaces of intravenous catheters. Journal of Infectious Diseases 146:479-482. 